\title{
Renosplenic Shunting in the Nutcracker Phenomenon: A Discussion and Paradigm Shift in Options? A Novel Approach to Treating Nutcracker Syndrome
}

\author{
$\mathrm{Ng}$ Deborah Chieh Yih, MBBS ${ }^{1,2}$ Lee Hwee Chyen, MBBS ${ }^{1}$ Yang Cunli, MBBS, FRCR ${ }^{3}$ \\ Punamiya Sundeep Jaywantraj, MBBS, FAMS ${ }^{3,4}$ Azucena Benedict Cesar Isip, MBBS ${ }^{1}$ \\ Sule Ashish Anil, MBBS, MD (Int Med), MRCP (UK), FAMS (Int Med), FICA, FRCP(UK), \\ European Hypertension Specialist (ESH specialist) $)^{1,5}$
}

${ }^{1}$ Department of General Medicine, Tan Tock Seng Hospital, Singapore
2 Department of General Surgery, Tan Tock Seng Hospital, Singapore
${ }^{3}$ Department of Diagnostic Radiology, Tan Tock Seng Hospital,
Singapore
${ }^{4}$ Subspecialty of Interventional Radiology, Tan Tock Seng Hospital,
Singapore
${ }^{5}$ Subspecialty of Vascular Medicine, Tan Tock Seng Hospital, Singapore

Address for correspondence Dr. Ashish Anil Sule, MBBS, MD, MRCP (UK), FAMS, FICA, FRCP (UK), 11 Jalan Tan Tock Seng, Tan Tock Seng Hospital, Singapore 308433 (e-mail: ashish_anil@ttsh.com.sg).

Int J Angiol 2014;23:71-76.

\begin{abstract}
Keywords

- nutcracker syndrome

- renosplenic shunting

- splenorenal shunting

- left renal vein compression

- renosplenic bypass

- hematuria

- chronic pelvic pain

- laparoscopic

- minimally invasive surgery

The nutcracker syndrome is a rare clinical manifestation of symptoms caused by the compression of the left renal vein by an overriding superior mesenteric artery, an anatomical variant otherwise known as the nutcracker phenomenon. Usually present in women and children, when symptomatic, it commonly presents with hematuria, proteinuria, and chronic pelvic pain. Effective modalities of treatment apart from conservative management, include both invasive surgical procedures such as renal vein transposition and autotransplantation of the kidney and more popular recently, the less invasive endovascular stenting. Both options, however, are not without complications, such as, retroperitoneal hematomas or stent migration, thrombosis and restenosis. We now present a case of spontaneous renosplenic shunting in a 68-year-old lady of Chinese descent with the nutcracker syndrome-the first of such cases to be ever reported in a patient with no preexisting predilection for chronic liver disease and portosystemic shunting. Despite having significant pelvic venous congestion as evident on computed tomography scans, she remained asymptomatic. This may present a novel paradigm shift for the treatment of the nutcracker syndrome - surgical creation of a renosplenic bypass instead of current modalities, an alternative solution which can be performed laparoscopically and is without problems related to stent use. The creation of laparoscopic splenorenal bypass has been reported once thus far in Cleveland Ohio by Chung and Gill with good symptomatic improvement but no further studies since to validate its long-term effectiveness.
\end{abstract}

First reported in 1950 by El-Sadr and Mina, ${ }^{1}$ the nutcracker phenomenon is a rare anatomical variant caused by compression of the left renal vein by an overriding superior mesen- teric artery near its point of origin. The term "Nutcracker Syndrome" was subsequently coined by de Schepper ${ }^{2}$ in 1972 to be a clinically symptomatic form of the phenomenon, and
Copyright $\odot 2014$ by Thieme Medical Publishers, Inc., 333 Seventh Avenue, New York, NY 10001, USA. Tel: +1(212) 584-4662.
DOI http://dx.doi.org/ 10.1055/s-0033-1348883. ISSN 1061-1711. 
on the basis of limited cases reported in literature, it occurs most commonly in women and children. It usually presents in the second or third decade, and may present with hematuria, proteinuria, ${ }^{3}$ chronic pelvic pain syndromes, ${ }^{4}$ abdominal pain, varicoceles formations or rupture. ${ }^{5}$ It is also associated with low body mass index, orthostatic disturbances, ${ }^{6}$ and fatigue, with studies documenting improvement in fatigue upon relief of pelvic compression.

Various reports describe cases of the nutcracker syndrome coexisting with the superior mesenteric artery (SMA) syndrome, a close cousin and more well-known syndrome involving compression of the duodenum by the SMA.

The diagnosis of the nutcracker syndrome is made when the phenomenon is accompanied by clinical symptoms. Radiological evidence (e.g., Doppler ultrasonography or computed tomography), as well as hemodynamic changes which can be quantified via angiography and retrograde venography, both gold standard choices are also recommended. A renocaval pressure gradient of $>3 \mathrm{~mm} \mathrm{Hg}$ is required before a definite diagnosis of the nutcracker syndrome is made ${ }^{8}$ (pressure gradients in normal individuals have been found to be $<1 \mathrm{~mm} \mathrm{Hg}^{9}$ ), however, having said that, the pressure gradients also often vary with hydration and degree of collateralization.

In terms of treatment options, depending on degree of symptoms, they can range from conservative follow-ups to invasive surgical procedures, and more recently the less invasive endovascular stenting. ${ }^{10-14}$ These however are not without complications. Left renal vein transposition, for example, the most commonly used procedure to date, ${ }^{15}$ has known complications of left renal vein thrombosis, as well as development of retroperitoneal hematomas ${ }^{16}$ post operatively, which may require further invasive surgical revisions. One case even required nephrectomy ${ }^{17}$ because of the failure of normalization of renocaval pressures with recalcitrant recurrent hematuria postoperatively. The recently more popular, less invasive endovascular stenting also has complications such as stent migration, thrombosis, and restenosis and may even require anticoagulation.

We now present a unique case of an asymptomatic elderly Asian lady who was incidentally found to have the nutcracker phenomenon after an admission for fall likely precipitated by a urinary tract infection.

\section{Case Presentation}

A 68-year-old lady with no medical history first presented to us with an accidental fall. She sustained a closed right lateral malleolus fracture and was managed conservatively with a cast. She reported a 2-day history of poor appetite with no respiratory, abdominal, or lower urinary tract symptoms. She also had no easy bruisability or bleeding manifestations. There was also no history of drinking, smoking, or ingestion of traditional medications.

On examination, she was found to be febrile at $37.8^{\circ} \mathrm{C}$. The rest of her vital signs (blood pressure, 152/81; heart rate, 90; oxygen saturation as measured by pulse oximetry, $\mathrm{Spo}_{2} 98 \%$ on room air) and physical examination was unremarkable.
Laboratory investigations revealed thrombocytopenia (platelets, $83 \times 10^{9} / \mathrm{L}$; normal range, $170-420 \times 10^{9}$; hemoglobin, $11.8 \mathrm{~g} / \mathrm{dL}$; normal range, $11 / 0-15.0 \mathrm{~g} / \mathrm{dL}$; white blood cells, $6.4 \times 10^{9} / \mathrm{L}$; normal range, 3.6-9.3 $\times 10^{9} / \mathrm{L}$ ), microscopic hematuria and significant growth of urinary klebsiella pneumonia sensitive to beta-lactam antibiotics (urinalysis: red blood cells, 20 cells/ $\mu \mathrm{L}$; normal range, $0-13$ cells $/ \mu \mathrm{L}$; white blood cells, 15 cells $/ \mu \mathrm{L}$; normal range, $0-6$ cells $/ \mu \mathrm{L}$; squamous epithelial cells 2 , Bacteria $3+$ ). In addition, there was also mild elevation of aspartate transaminase (AST) and bilirubin (total bilirubin, $41 \mu \mathrm{mol} / \mathrm{L}$; normal range, 7-31 $\mu \mathrm{mol} / \mathrm{L}$; alanine transaminase, $32 \mathrm{U} / \mathrm{L}$; normal range, 14-54 U/L; AST, $67 \mathrm{U} / \mathrm{L}$; normal range, 15-41 U/L; alkaline phosphatase, $60 \mathrm{U} / \mathrm{L}$; normal range, 38-126 U/L) which subsequently led to an ultrasound of her abdomen being performed. The rest of her laboratory investigations (renal function, electrolytes, coagulation profile, and chest X-ray) were normal.

The ultrasound revealed a normal liver size and parenchymal echogenicity and a normal splenic size of $9.3 \mathrm{~cm}$. However, moderate splenic varices were also seen. A computed tomography (CT) of the abdomen and pelvis was then subsequently performed which revealed a splenorenal shunt with compression and dilatation of the left renal vein by the superior mesenteric artery as it branches out of the abdominal aorta. The left ovarian vein which drained into the left renal vein was also prominent with congestion of pelvic veins. Radiological appearances of the liver and spleen were normal (see - Figs. 1-4).

The case was discussed at a hospital-based multidisciplinary vascular surgery- diagnostic radiology meeting and subsequent follow-up on the basis of symptom development was recommended. An oesophageogastroduodenoscopy to check for unlikely gastric varices was also suggested and was planned to be discussed with the patient at a later date. The patient, however, declined and opted to return if she developed any future symptoms. Her urinary tract infection was treated with 1 week of Augmentin with resolution of the fever and she was followed up thereafter with her general practitioner. Subsequent repeat urine dipstick tests at 3 months also showed clearance of the infection. Serial



Fig. 1 CT AP transverse plane showing prominent distal left renal vein (B) caused by compression of overriding superior mesenteric artery $(A)$. 


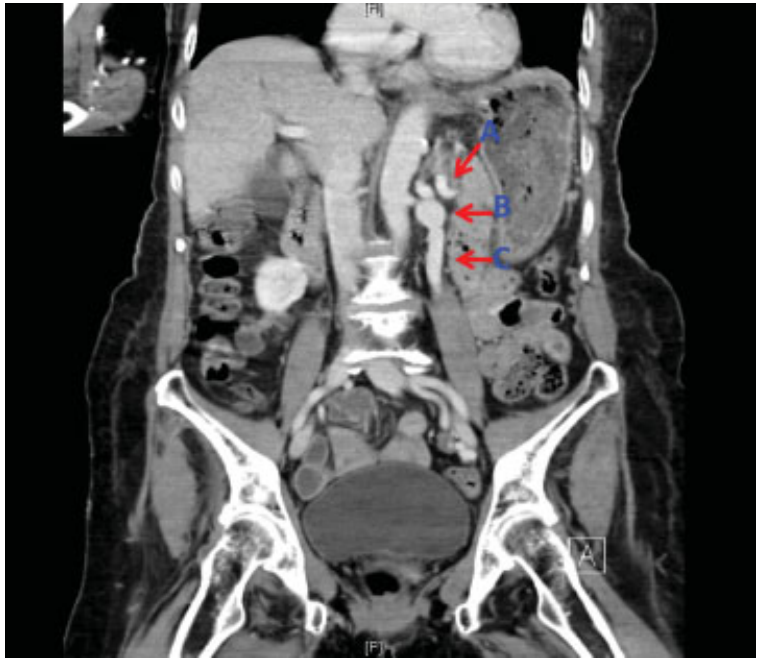

Fig. 2 CT AP coronal plane demonstrating reno- splenic shunt (A), dilated renal vein $(B)$, overriding superior mesenteric artery $(C)$.

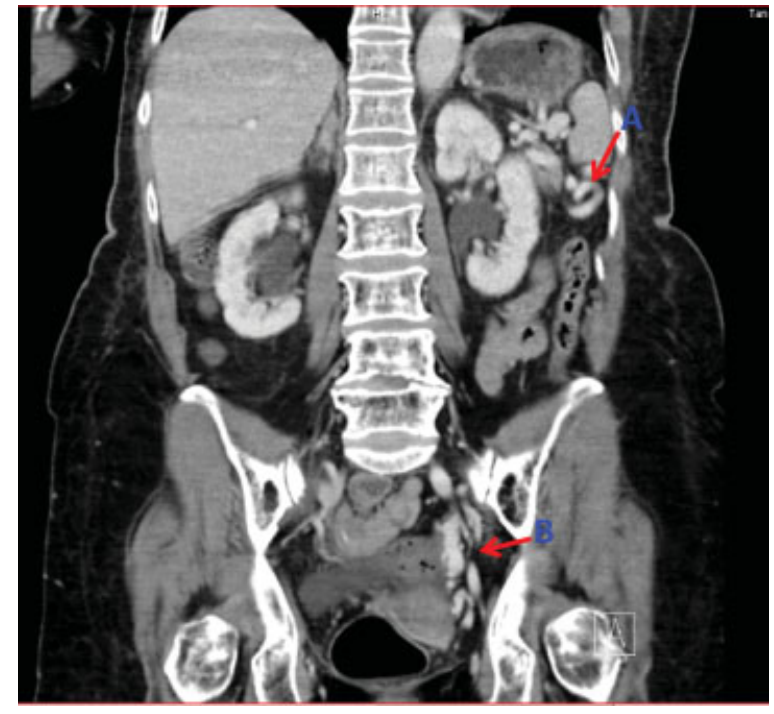

Fig. 3 CT AP coronal plane demonstrating spleenic varicosities (A), pelvic venous congestion (B).

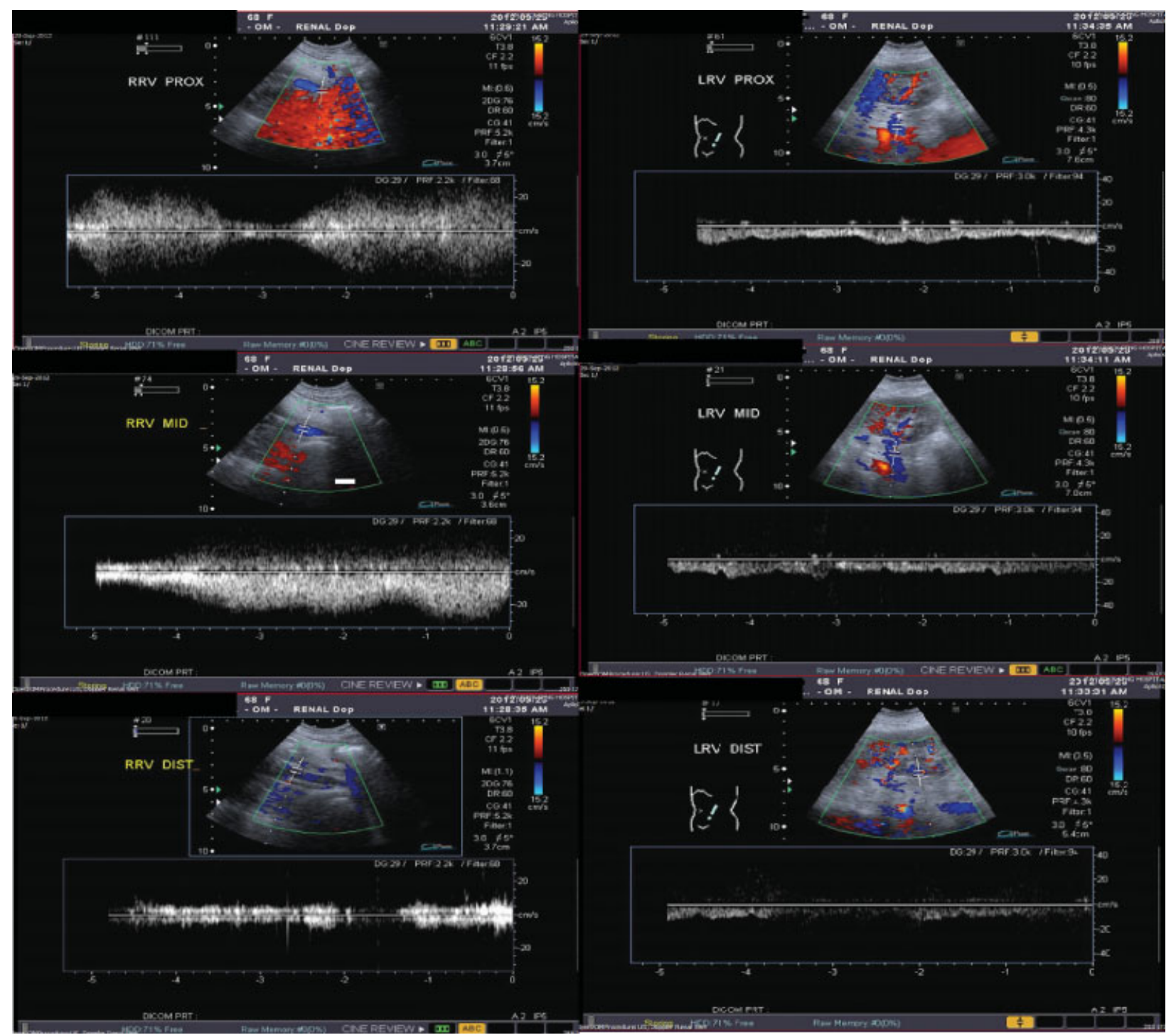

Fig. 4 US Doppler renal veins demonstrating reduced renal flow distally in the left renal vein due to compression by overriding superior mesenteric artery. 
laboratory tests also showed normalization of both her platelet counts and liver panel.

This case illustrates a unique combination of spontaneous splenorenal shunting in a patient with the nutcracker phenomenon. To date, only one other case report ${ }^{8}$ has been reported, but describes the nutcracker phenomenon and splenorenal shunting in a patient who also had a background of Grade C Child-Pugh alcoholic cirrhosis, which could well account for the portal hypertension and portosystemic anastomosis.

\section{Discussion}

As alluded to earlier, left renal vein transposition, and now increasingly popular, endovascular stenting, are the most commonly used treatment modalities for the nutcracker syndrome. This shift towards avoiding excessive invasiveness has shown promising long-term results ${ }^{10-14}$ and one study has also concluded "all surgical operations effective except for excessive invasiveness". ${ }^{18}$ With progression and sophistication of surgical techniques and instruments, laparoscopic minimally invasive surgery would naturally be a development to look forward to.

Recently, Chung and Gill ${ }^{19}$ from Cleveland, Ohio had successfully performed laparoscopic surgery on a symptomatic 29-year-old lady with severe flank pain secondary to the nutcracker phenomenon. They had used a novel technique of creating a renosplenic bypass laparoscopically and with good success. This was done with a warm ischemic time of only 37 minutes, with immediate reduction of left renal vein distension and doubling of splenic vein diameter intraoperatively and absolute symptomatic resolution at her 8th month follow-up. Unfortunately, no figures to demonstrate objective improvement hemodynamically as the patient declined further investigations.

\section{Conclusion and Future Plans}

This first reported case of spontaneous renosplenic shunting in an elderly lady with the nutcracker phenomenon, who had radiological demonstration of chronic prominent pelvic venous congestion, but had never presented symptomatically, may suggest and further support the use of the above mentioned novel approach of creating renosplenic bypasses laparoscopically as an alternative and upcoming treatment option for the nutcracker syndrome.

Certainly, more studies have to be done before such a treatment can be validated as superior to endovascular stenting and left renal vein transposition. And the presence of a renosplenic shunt alone may not be able to account for absolute transition from a decompensated congested renal vein to a compensated one as there are other asymptomatic patients with the nutcracker phenomenon who do not have the spontaneous renosplenic collateral. It is however without doubt that the prospect of alternative treatment via minimally invasive laparoscopic surgery is an exciting one. Another group from Shanghai, China, ${ }^{20}$ has also recently described good anecdotal results from laparoscopic inferior mesenteric-gonadal vein bypass.

This minimally invasive method of creating bypasses can also be extrapolated to the treatment of other conditions which may result in congestion of the left renal vein, such as pancreatic neoplasms and retroperitoneal tumors. ${ }^{5}$ Furthermore, surgical creation of bypass do not have problems associated with stent use such as stent migration ${ }^{11}$ or the need for monitoring of coagulation status. (see - Fig. 5)

It is, thus, a worthwhile option to consider and more longterm studies should be done to evaluate its effectiveness and safety.

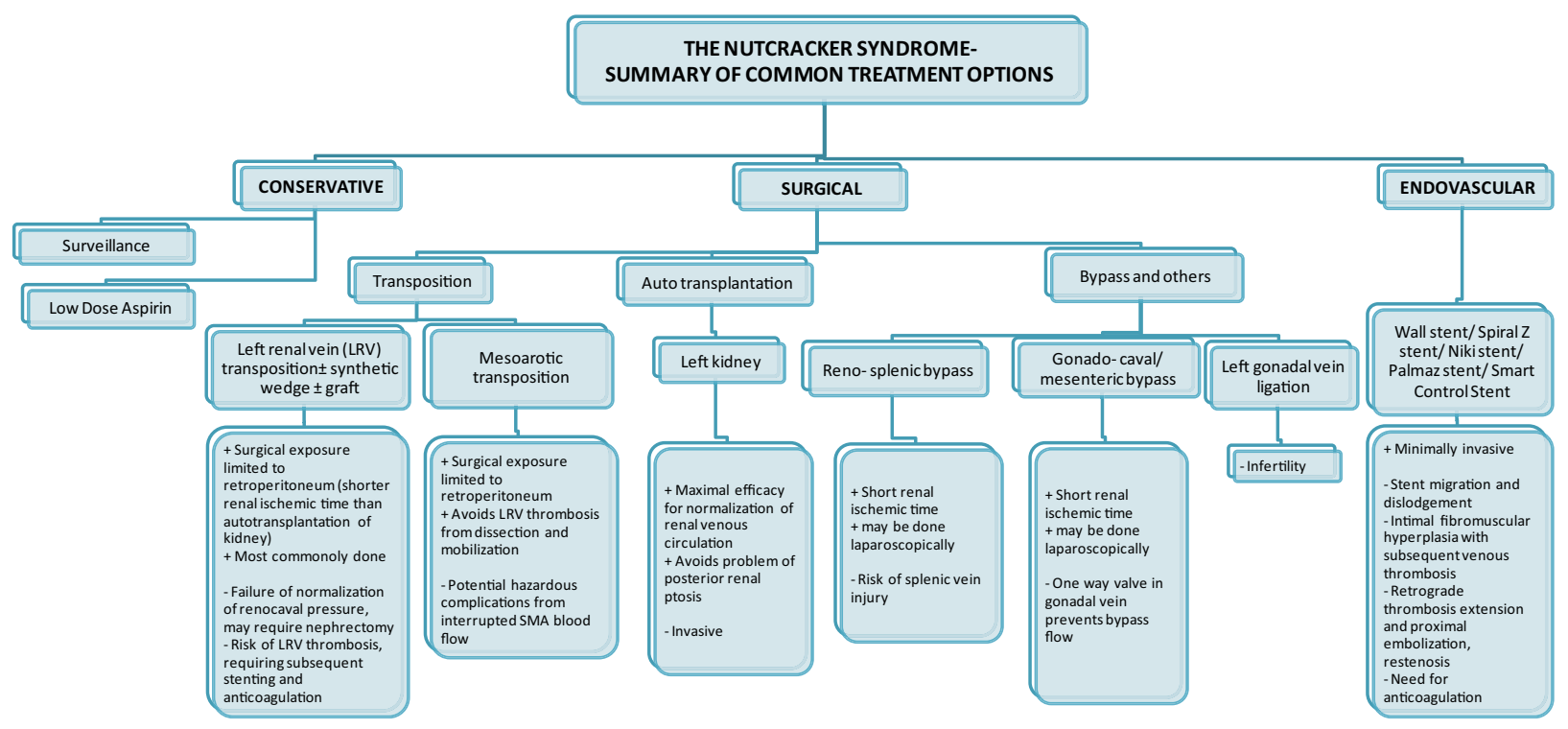

Fig. 5 Summary of treatment options for the nutcracker syndrome. 


\section{Acknowledgments}

We thank Dr. Gavin Lim Hock Tai, Dr. Ting Yonghan, Dr. Ankit Tandon, Dr. S Sarat Kumar for reporting the radiological scans. Special thanks also to Dr. Lee Weiyong, Dr. Narayanan Sriram, Dr. Shanker Pasupathy, and Dr. Tan Ek Khoon for their valuable comments and feedback.

\section{References}

1 El-Sadr AR, Mina E. Anatomical and surgical aspects in the operative management of varicocele. Urol Cutaneous Rev 1950;54 (5):257-262

2 de Schepper A. ["Nutcracker" phenomenon of the renal vein and venous pathology of the left kidney]. [in Dutch] J Belge Radiol 1972;55(5):507-511

3 Ekim M, Ozçakar ZB, Fitoz S, et al. "Nutcracker" fenomeen van de vena renalis en veneuze pathologie van de linker nier (in Dutch). Clin Nephrol 2006;65(4):280-283

4 Scultetus AH, Villavicencio JL, Gillespie DL. The nutcracker syndrome: its role in the pelvic venous disorders. J Vasc Surg 2001;34 (5):812-819

5 Kurklinsky AK, Rooke TW. Review: Nutcracker phenomenon and nutcracker syndrome. Mayo Clin Proc 2010;85(6):552-559

6 Takemura T, Iwasa H, Yamamoto S, et al. Clinical and radiological features in four adolescents with nutcracker syndrome. Pediatr Nephrol 2000;14(10-11):1002-1005

7 Takahashi Y, Sano A, Matsuo M. An effective "transluminal balloon angioplasty" therapy for pediatric chronic fatigue syndrome with nutcracker phenomenon. [letter] Clin Nephrol 2000;53(1):77-78

8 Ahmed K, Sampath R, Khan MS. Current trends in the diagnosis and management of renal nutcracker syndrome: a review. Eur J Vasc Endovasc Surg 2006;31(4):410-416

9 Beinart C, Sniderman KW, Tamura S, Vaughan ED. JrSosTA. Left renal vein to inferior vena cava pressure relationship in humans. J Urol 1982;127(6):1070-1071
10 Daily R, Matteo J, Loper T, Northup M. Nutcracker syndrome: symptoms of syncope and hypotension improved following endovascular stenting. Vascular 2012;20(6):337-341 [Epub ahead of print]

11 Liu Y, Sun Y, Wu XJ, Jiang Y, Jin X. Endovascular stent placement for the treatment of nutcracker syndrome. Int Urol Nephrol 2012;44 (4):1097-1100

12 Wang X, Zhang Y, Li C, Zhang H. Results of endovascular treatment for patients with nutcracker syndrome. J Vasc Surg 2012;56 (1):142-148

13 Segawa N, Azuma H, Iwamoto Y, Sakamoto T, Suzuki T, Ueda H, Yamamoto K, Shimizu T, Kichikawa K, Katsuoka Y. Expandable metallic stent placement for nutcracker phenomenon. Urology 1999;53(3):631-633

14 Chen S, Zhang H, Shi H, Tian L, Jin W, Li M. Endovascular stenting for treatment of Nutcracker syndrome: report of 61 cases with long-term followup. J Urol 2011;186(2):570-575

15 Rudloff U, Holmes RJ, Prem JT, Faust GR, Moldwin R, Siegel D. Mesoaortic compression of the left renal vein (nutcracker syndrome): case reports and review of the literature. Ann Vasc Surg 2006;20(1):120-129

16 Reed NR, Kalra M, Bower TC, Vrtiska TJ, Ricotta JJ II, Gloviczki P. Left renal vein transposition for nutcracker syndrome. J Vasc Surg 2009;49(2):386-393, discussion 393-394

17 Hohenfellner M, D'Elia G, Hampel C, Dahms S, Thüroff JW. Transposition of the left renal vein for treatment of the nutcracker phenomenon: long-term follow-up. Urology 2002;59(3): 354-357

18 Zhang H, Li M, Jin W, San P, Xu P, Pan S. The left renal entrapment syndrome: diagnosis and treatment. Ann Vasc Surg 2007;21 (2):198-203

19 Chung BI, Gill IS. Laparoscopic splenorenal venous bypass for nutcracker syndrome. J Vasc Surg 2009;49(5):1319-1323

20 Xu D, Gao Y, Chen J, Wang J, Ye J, Liu Y. Laparoscopic inferior mesenteric-gonadal vein bypass for the treatment of nutcracker syndrome. J Vasc Surg 2013; [Epub ahead of print] 